\title{
Analysis of the factors involved in cosmetic failure following excision of the eye
}

\author{
D L SMERDON AND G A SUTTON \\ From the Birmingham and Midland Eye Hospital
}

SUMMARY We graded the overall cosmetic outcome of 56 patients who required excision of the eye. Each patient was then subjected to a more detailed analysis of the specific abnormalities associated with excision of the eye in order to discover which are associated most consistently with a poor cosmetic result. The only factor showing a statistically significant variation with the overall cosmetic outcome was the degree of upper lid sulcus. Taken individually the other features showed no statistically significant correlation. When each finding was scored, the averaged sum of the scores was related to cosmetic outcome with statistical significance. A method of quantifying orbital volume loss is described.

Excision of the eye is indicated for inoperable intraocular malignancy, when there is a substantial risk of sympathetic ophthalmitis, endophthalmitis with failed treatment, and for a blind, painful eye.' As there is such a wide variation in cosmetic outcome, it would be an advantage to know the features associated with cosmetic failure. It might then be possible to alter methods of excision in order to reduce their incidence. This would in turn reduce the need for subsequent corrective procedures.

Some features associated with excision of the eye are well known. Enucleation in childhood results in a reduced orbital volume..$^{2-1}$ In adults there is a reduction in orbital volume which is either immediate or may be delayed. ${ }^{2-}$ Excision of the eye is said to be associated with the development of an upper lid sulcus, and this has stimulated the introduction of many varied surgical corrective techniques. ${ }^{5-8}$ Movement of the artificial eye, even with the better magnetic implants, is relatively poor. Cosmetic result and movement are said to be better when an orbital implant is used after enucleation ${ }^{5911}$ or after evisceration.

To discover more about the factors associated with poor cosmetic outcome we examined a group of patients who had undergone excision of the eye. Our aims were as follows: (1) to determine whether the apparent orbital volume loss which exists after excision of the eye could be measured clinically; (2) to assess the contribution of any other detectable

Correspondence to David Smerdon, FRCS, North Riding Infirmary, Newport Road, Middlesbrough, Cleveland TS1 5JE. anatomical or functional abnormalities to overall cosmetic result; (3) to determine whether the presence of an orbital implant was associated with a better overall cosmetic result; (4) to determine whether cosmetic outcome was influenced by the choice of excision procedure (evisceration rather than enucleation); (5) to see if age, sex, and aetiology were related to cosmetic outcome.

\section{Materials and methods}

From the Birmingham and Midland Eye Hospital operating theatre register we obtained the details of each patient who had undergone excision of the eye

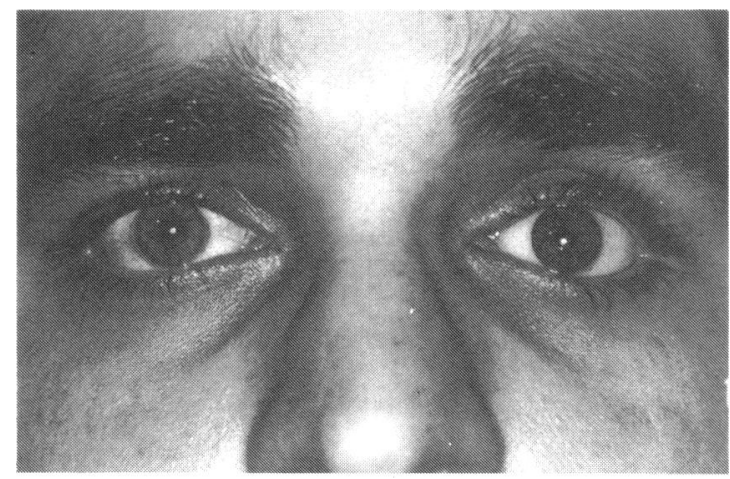

Fig. 1A

Fig. 1 Photographs taken in primary position (A), looking right (B), and looking left (C). 


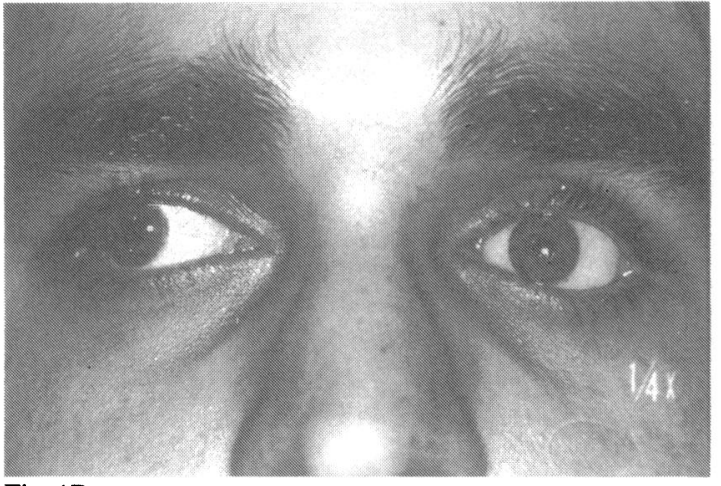

Fig. 1B

from 1 September 1979 to 13 May 1985. These details were used to trace the corresponding medical records. The patients were recalled by letter.

The following details were recorded: enucleation date; patient's age at enucleation; side; reason for enucleation; implant size and type (if inserted).

The patient was then photographed in the primary position, and looking right and left (Figs. 1a, b, c). We looked specifically for laxity of the lower lid.

The artificial eye (AE) was then removed, weighed (to 2 decimal points of a gram), and its volume determined by displacement in a graduated cylinder (to the nearest $0.5 \mathrm{~cm}^{3}$ ).

Each patient was subjected to volumetric analysis of their orbits. This was performed as follows. The AE was removed. A drop of oxybuprocaine was instilled into both the good eye and the socket. The patient put on a pair of Speedo swimming goggles which had a 0.25 inch $(6 \mathrm{~mm})$ hole drilled through the medial aspect of each of the flat anterior faces (Fig 2). The goggles were adjusted for symmetry on the orbital margins and the patient placed supine. Each chamber of the goggles was filled with normal saline fed from a $20 \mathrm{ml}$ syringe via a narrow cannula (a

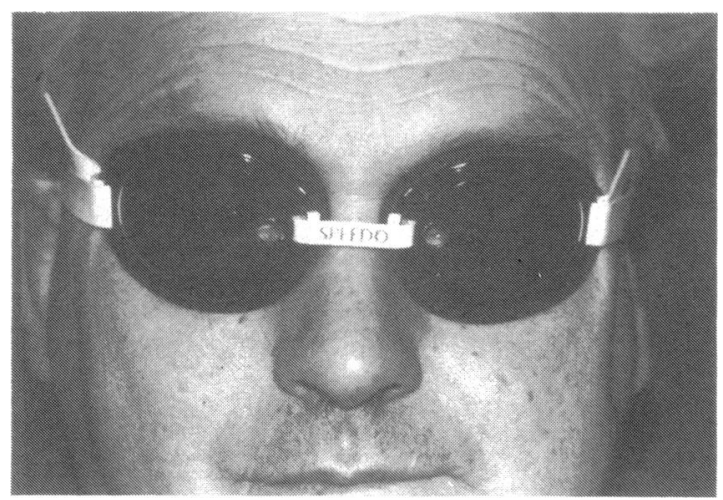

Fig. 2 The fenestrated goggles.

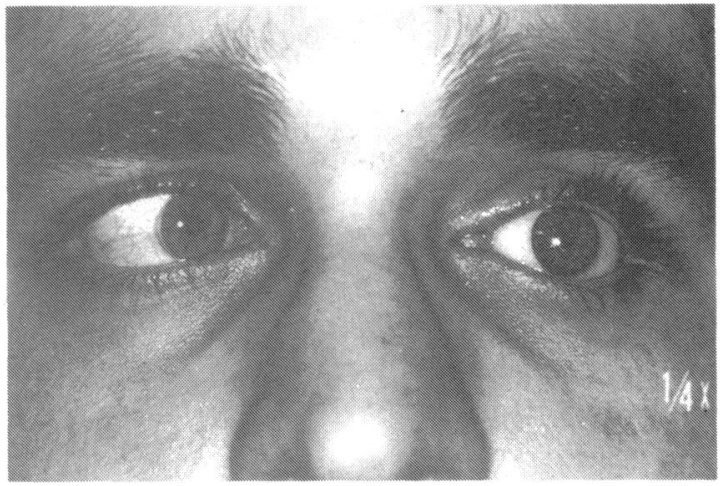

Fig. 1C

truncated 21g Butterfly - Fig. 3) and the volume recorded. The fluid was aspirated out through the same cannula, the AE was reinserted, and the patient was thanked and discharged.

Later the photographs were assessed, firstly for an overall impression of cosmetic outcome, and secondly to quantify the excision related abnormalities.

Overall cosmetic assessment was performed as follows. The photographs in the primary position were graded by both an ophthalmologist and a lay - person to ensure minimal bias. No grading was given until all the photographs had been seen, so that the extremes of cosmetic variability were known. Each patient was then allocated to one of five groups (scored 1-5 from best to worst) representing the range of cosmetic results which we encountered.

Any abnormalities related to excision were to be measured directly from the photographs and converted to $\mathrm{mm}$. The subjects would then be divided into their cosmetic groups and the results subjected to paired Student's $t$ tests to assess whether any perceived trends were of statistical significance.

Examination of the photographs in dextro- and

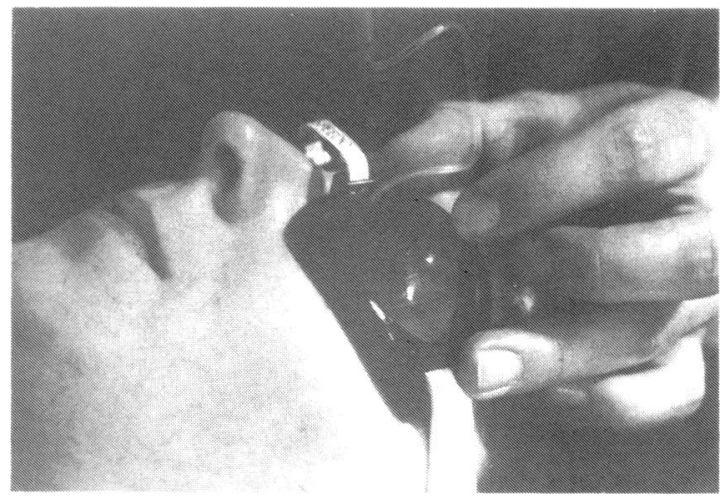

Fig. 3 The fenestrated goggles in use. 


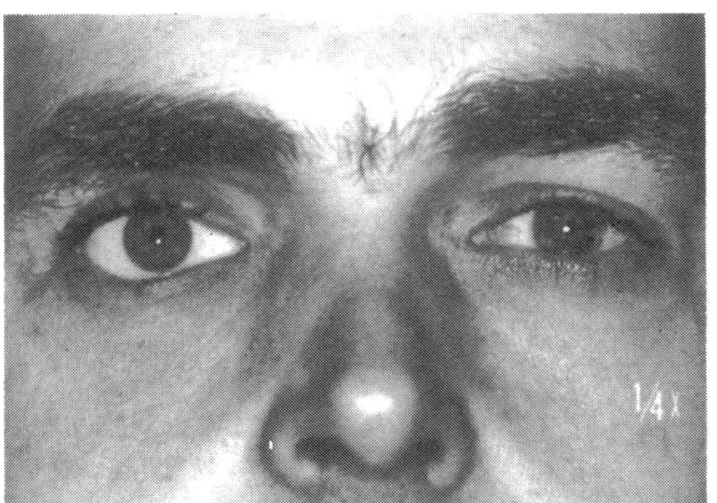

Fig. 4 Difference in height of palpebral apertures.

laevoversion allowed estimation of the ratio of movement of the eyes. The profile of an AE is such that measurement by the Hirschberg test is highly misleading. We used the change which occurs in the canthus-to-limbus measurement on versions to give a ratio of eye movements. These measurements were taken directly from the photographs.

\section{Results}

Over the six-year period 179 eyes were excised. There were 15 eviscerations and 164 enucleations. Eleven records were untraceable. Two patients were known to have died, and 18 others were deemed unsuitable for reasons of health (4), mental state (2), now distant location (12), and not recalled. A total of 148 patients were sent for, but only 56 attended. Four were excluded from analysis, three because of lost photographs and one who refused volumetric measurements. Unfortunately no evisceration patients were included in the analysis.

We recorded a number of abnormalities associated with excision of the eye: orbital volume loss $(52$,
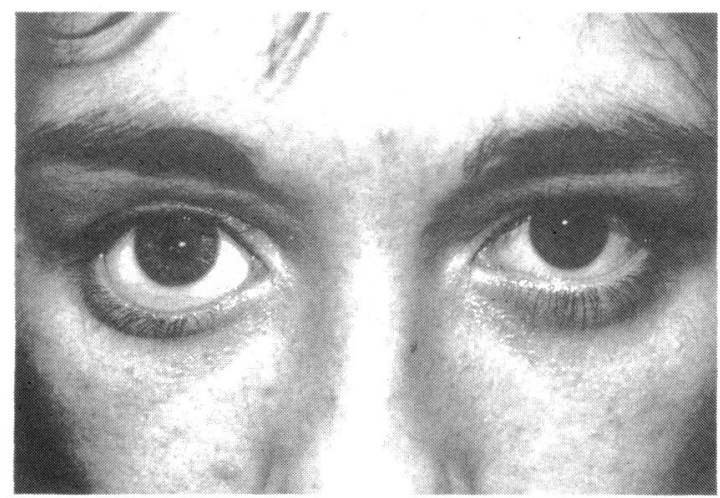

Fig. 6 Altered lower lid contour and lower lid laxity.

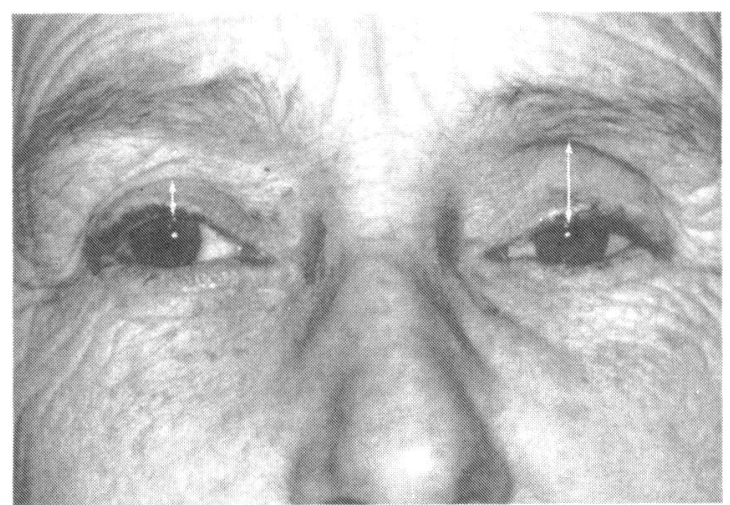

Fig. 5 Upper lid sulcus showing measurement points.

$100 \%$ ); difference in the height of the palpebral apertures $(25,48 \%$ ) (Fig. 4); poor movement $(52,100 \%)$ (Figs. 1a, b , c); the presence of an upper lid sulcus $(51,98 \%)$ (Fig. 5); laxity of the lower lid $(36,69 \%)$ (Fig. 6); altered lower lid contour $(34,65 \%)$ (Fig. 6); poor centring of the cosmetic shell $(36,69 \%)$ (Fig. 7$)$.

There were a number of other features which were AE fitting problems such as: medial edge of the $\mathrm{AE}$ visible on abduction ( 4 cases); poor $\mathrm{AE}$ colour match (3 cases); lateral edge of AE visible on adduction (1 case).

The numbers in each cosmetic group are given in column 1 of Table 1.

Orbital volumetric analysis was easy to perform and was not uncomfortable for the patient. Measurements repeated for various reasons were found to vary by less than $1 \mathrm{ml}$. The averages of the volumetric results are shown against cosmetic grouping in columns $2-5$ of Table 1 . There was a wide variation in both the enucleated and normal eye volumes ( $\mathrm{E}$ vol and $\mathrm{N}$ vol respectively). The formula ( $\mathrm{E} \mathrm{vol}-\mathrm{N}$ vol) gives the orbital volume loss (OVL). If the shell

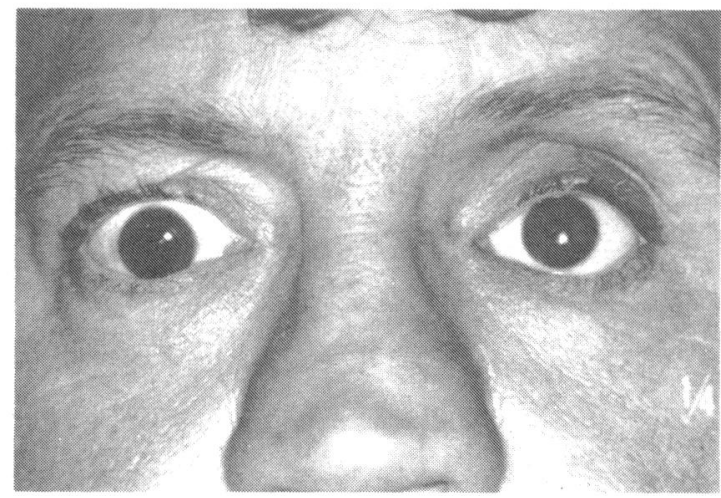

Fig. 7 Poor centring of the artificial eye. 
Table 1 Averages of measurements of volumetric analysis, shell weight and volume, palpebral apertures, movement ratio, and lid sulcus against cosmetic group

\begin{tabular}{|c|c|c|c|c|c|c|c|c|c|c|c|c|c|c|c|}
\hline \multirow{2}{*}{$\begin{array}{l}\text { Cosmetic } \\
\text { group }\end{array}$} & \multirow[b]{2}{*}{$n$} & \multicolumn{4}{|c|}{ Volumetric analysis } & \multicolumn{2}{|c|}{ Shell } & \multicolumn{3}{|c|}{ Palpebral aperture } & \multirow{2}{*}{$\begin{array}{l}\text { Movement } \\
\text { ratio }\end{array}$} & \multicolumn{4}{|c|}{ Lid sulcus } \\
\hline & & Evol & $N$ vol & $O V L$ & $O V D$ & $W t$ & Vol & $N$ & $E$ & $P A D$ & & $N$ & $E$ & $E$ & $-N$ \\
\hline Very poor & 3 & 18 & 12 & 5 & 2 & 3 & 3 & 7 & 8 & -1 & $5: 1$ & 3 & 11 & 8 & \\
\hline Poor & 5 & 15 & 12 & 5 & 1 & 3 & 3 & 9 & 9 & 0 & $3: 1$ & 3 & 8 & 5 & $\begin{array}{l}p>0.05 \\
n>0.1\end{array}$ \\
\hline Average & 21 & 19 & 14 & 5 & 3 & 3 & 3 & 9 & 9 & 0 & $4: 1$ & 3 & 6 & 3 & $\begin{array}{l}p>0 \cdot 1 \\
p>0 \cdot 01\end{array}$ \\
\hline Good & 18 & 18 & 14 & 4 & 2 & 3 & 3 & 10 & 10 & 0 & $2: 1$ & 3 & 5 & 2 & $p>0.01$ \\
\hline \multirow[t]{5}{*}{ Very good } & 5 & 18 & 15 & 3 & 0 & 3 & 3 & 9 & 9 & 0 & $3: 1$ & 3 & 4 & 1 & \\
\hline & $\min$ & 9 & 6 & -1 & -2 & 1 & 1 & 5 & 5 & -4 & $1 \cdot 1: 1$ & 0 & 0 & 1 & \\
\hline & $\max$ & 26 & 19 & 11 & 8 & 5 & 4 & 13 & 14 & 3 & $7 \cdot 7: 1$ & 8 & 14 & 8 & \\
\hline & mean & 19 & 14 & 5 & 2 & 3 & 3 & 9 & 9 & 0 & $3: 1$ & 3 & 6 & 3 & \\
\hline & SD & $3 \cdot 6$ & $2 \cdot 5$ & $2 \cdot 5$ & $2 \cdot 4$ & 1.0 & 0.7 & 1.8 & $2 \cdot 1$ & 1.6 & $1 \cdot 4: 1$ & $2 \cdot 1$ & $3 \cdot 2$ & $2 \cdot 3$ & \\
\hline
\end{tabular}

$\mathrm{E}=$ enucleated eye. $\mathrm{N}=$ normal eye. $\mathrm{OVL}=$ orbital volume loss $(\mathrm{E}$ vol- $\mathrm{N}$ vol $) . \mathrm{OVD}=$ orbital volume discrepancy. $\mathrm{PAD}=$ difference in height of palpebral apertures. NS $=$ not significant .

volume is added to this figure, ideally there should be a figure of zero. We have termed this the orbital volume discrepancy (OVD). The mean of the orbital volume loss was $6 \mathrm{ml}$ (SD 2.3) in those without an orbital implant and $4 \mathrm{ml}$ (SD 2.5) in those with. The mean of the OVD in each group was $4 \mathrm{ml}(\mathrm{SD} 2 \cdot 4)$ and $2 \mathrm{ml}(\mathrm{SD} 2 \cdot 3)$ respectively.

We found that shell volume was broadly related to shell weight, though neither measurement was related to cosmetic result (columns 6 and 7 of Table $1)$. Those patients without orbital implants $(10$, $19 \cdot 2 \%$ ) had a mean shell weight of $3 \cdot 1 \mathrm{~g}$ (SD 0.9) as compared with $2.8 \mathrm{~g}$ (SD 1.1) in those with implants.

There were 25 cases $(48 \%)$ in which there was a difference in the palpebral aperture of over $1 \mathrm{~mm}$. Neither measurement of the palpebral apertures nor their differences showed any consistent variation with cosmetic group (columns 8-10 of Table 1).

All 52 patients $(100 \%)$ showed reduction in the ratio of $\mathrm{AE}$ movement as compared with the fellow eye (column 11 of Table 1 ).
In 51 cases $(98 \%)$ a lid sulcus was demonstrated, and the averaged measurements are shown against cosmetic group in columns 13-15 of table 1. For the purposes of measurement the lid sulcus was taken to be the difference between distances from upper lid margin to first skin crease (Fig. 5). There was a statistically significant correlation between cosmetic group and the extent of the lid sulcus.

There were 36 cases $(69 \%)$ of lower lid laxity and 34 cases $(65 \%)$ of altered lower lid contour. These were scored 0-4, from most normal to most abnormal. Averaged scores decreased with better cosmetic groups, though not with statistical significance (columns 2 and 3 of Table 2 ).

Centring and movement of the $\mathrm{AE}$ with respect to the normal eye are also shown in Table 2 (columns 4 and 5). Thirty six patients $(69 \%)$ had some degree of poor AE centring. Horizontal and vertical centring was scored separately as follows: a score of 0 was given on each scale if the eye was correctly centred. If the $\mathrm{AE}$ was slightly decentred, a score of 1 was given

Table 2 Cosmetic groups against presence of an orbital implant, averages of scores for lower lid laxity, altered lower lid contour, AE centring, and averaged total scores

\begin{tabular}{|c|c|c|c|c|c|c|c|c|}
\hline \multirow[b]{2}{*}{ Cosmetic group } & \multirow[b]{2}{*}{$n$} & \multicolumn{2}{|c|}{ Lower lid } & \multicolumn{2}{|l|}{ AE centring } & \multicolumn{2}{|c|}{ Implant } & \multirow{2}{*}{$\begin{array}{l}\text { Averaged } \\
\text { total scores }\end{array}$} \\
\hline & & Laxity & Contour & Horizontal & Vertical & Yes & No & \\
\hline Very poor & 3 & $2 \cdot 0$ & $1 \cdot 6$ & 0.6 & $1 \cdot 3$ & 1 & 2 & 11 \\
\hline Poor & 5 & $1 \cdot 4$ & $1 \cdot 4$ & $1 \cdot()$ & $1 \cdot 6$ & 3 & $\overline{2}$ & $8 \quad p>0 \cdot 1$ \\
\hline Average & 21 & $1 \cdot 1$ & $1 \cdot 1$ & 0.8 & $1 \cdot 0$ & 16 & 5 & $7 \mathrm{p}>0.05$ \\
\hline Good & 18 & $1 \cdot 0$ & $1 \cdot 0$ & 0.8 & $(0) 3$ & 18 & () & $5 \quad \mathrm{p}>0.05$ \\
\hline Very good & 5 & 0.4 & $0 \cdot 2$ & $0 \cdot 2$ & $(0 \cdot 2$ & 4 & 7 & $2 \mathrm{p}>0 \cdot 1$ \\
\hline
\end{tabular}

Scoring: $\begin{aligned} 0 & =\text { normal } \\ 1 & =\text { minimal } \\ 2 & =\text { moderate } \\ 3 & =\text { marked } \\ 4 & =\text { very marked }\end{aligned}$


Table 3 Age at enucleation and sex distribution against cosmetic result

\begin{tabular}{lcll}
\hline $\begin{array}{l}\text { Age at } \\
\text { enucleation }\end{array}$ & Male & Female & $\begin{array}{l}\text { Averaged scores } \\
\text { of cosmetic result }\end{array}$ \\
\hline $0-19$ & 4 & 2 & $1 \cdot 8$ \\
$20-39$ & 10 & 4 & $2 \cdot 3$ \\
$40-59$ & 11 & 5 & $2 \cdot 7$ \\
$60+$ & 7 & 9 & $3 \cdot 1$ \\
\hline
\end{tabular}

Scoring: $1=$ very good. $2=$ good. $3=$ average $.4=$ poor. $5=$ very poor .

(and the direction of decentring noted). A score of 2 was reserved for more marked decentring. Eighteen (35\%) were found to be correctly centred both horizontally and vertically, while $12(23 \%)$ were found to be centred neither horizontally nor vertically. Correct centring was found in $29(56 \%)$ AEs horizontally only and 29 vertically only. Of those AEs with inaccurate centring the common deviations were outwards and upwards. There was no strong correlation between cosmetic group and centring, but there were fewer AEs with both horizontal and vertical deviation in the better cosmetic groups.

We found that the absence of an orbital implant did not necessarily produce a worse cosmetic result, but that in general there was a smaller proportion of subjects without an implant in the better cosmetic groups and vice versa (columns 6 and 7 of table 2).

Table 3 shows the patients by age and sex. There were 32 males and 20 females. In groups of 20 years the figures showed a correlation with cosmetic result; the younger patients tended to show better cosmetic results.

There was no correlation between the reason for excision of the eye against cosmetic group (Table 4). The eyes were excised most commonly for choroidal melanoma and trauma (14 (27\%) each).

Finally we divided the subjects into their cosmetic groups and summed all the excision related features apart from movement ratio. AE centring, lid laxity, and lid contour were already scored for each subject. Lid sulcus and palpebral aperture measurements were in millimetres and, if added to the scores, would have induced considerable bias. To avoid this, both measurements were scored on a 5 point scale (0-1.5 $\mathrm{mm}=0,1 \cdot 6-3.0 \mathrm{~mm}=2,3 \cdot 1-4.5 \mathrm{~mm}=3$, $4 \cdot 6-6 \cdot 0 \mathrm{~mm}=4,6 \cdot 1-7 \cdot 5 \mathrm{~mm}=5$ ). A similar scale was used to score orbital volume loss. A statistically significant correlation was found, in that total scores were less in the better cosmetic groups. The results are summarised in column 8 of Table 2 .

\section{Discussion}

Our first aim was to see if excision related orbital
Table 4 Reason for enucleation against cosmetic result

\begin{tabular}{lrl}
\hline Reason for enucleation & $n$ & $\begin{array}{l}\text { Averaged scores } \\
\text { of cosmetic result }\end{array}$ \\
\hline Intraocular malignancy & 14 & $3 \cdot 0$ \\
Risk of sympathetic & 14 & $2 \cdot 5$ \\
Blind painful eye & 20 & $2 \cdot 6$ \\
Other & 4 & $2 \cdot 5$ \\
\hline
\end{tabular}

Scoring: $1=$ very good. $2=$ good. $3=$ average. $4=$ poor. $5=$ very poor.

volume loss could be measured. Orbital volume measurements have been done in the past, but only on skulls. ${ }^{3+}$ In vivo extrapolations have been made from linear measurements from radiographs ${ }^{34}$ or from CT scanning and image analysis, ${ }^{+}$which, though effective, is still relatively expensive. Exophthalmometry will give the relative positions of the cornea with respect to the orbital margin, but will give only a very rough idea of orbital volume changes. Although our method of measurement is indirect, it is a new, cheap, reproducible, and painless way of measuring orbital volume loss. As with exophthalmometry, the absolute figures cannot be used for comparisons between patients, and the test could be misleading in cases of marked facial asymmetry. In an otherwise normal patient the technique was quick and accurate.

As stated, we recorded seven features which were measurable departures from normal structure or function. Of these individual features the upper lid sulcus measurement was the only one to be correlated significantly with overall cosmetic result. Upper lid sulcus measurement has been described by Hill and Radford, ${ }^{7}$ who measured the anteroposterior depth of the sulcus. We considered that the vertical extent of the sulcus would be more likely to affect cosmetic appearance. Both the presence of lower lid laxity and altered lower lid contour were moderately correlated with cosmetic result, though not with statistical significance. There was no other individual correlation, though, when summed, all the excision related features were correlated with overall cosmetic result.

It has been suggested that many of the excision related abnormalities are linked. To compensate for either ptosis or orbital volume loss a larger artificial eye would be required. This heavier artificial eye would, by gravity, press against the supporting lower lid. This would lead to some of the other abnormalities such as lower lid laxity and altered lower lid contour. ${ }^{7}$ We thought this might in turn lead to the formation of an upper lid sulcus and the centring abnormalities. If this were true, one would expect those factors to be worse with increasing shell weight. This is not borne out by an analysis of the figures. We were unable to demonstrate any other correlations. 
There are theories about the aetiology of some of the excision related abnormalities. These were summarised by DeVoe in $1945 .{ }^{5}$ The most interesting postulated that the reduction in orbital volume changes the direction of pull of the levator from upwards (round the globe) to backwards, thus producing an upper lid sulcus. If this were true, a direct link would be expected between orbital volume loss and upper lid sulcus. We were unable to demonstrate this. If we had used Hill and Radfords' method of measurement,' such a correlation might have been found.

In enucleation with implant it is usual to suture the recti over or through the implant. The obliques are usually ignored. This abolishes their usual forward pull and may add to orbital volume loss and upper lid sulcus. This may account for the anecdotal reports of a better cosmetic result with evisceration where the muscle insertions are not disturbed. We had no evisceration patients in the analysis and so were unable to comment on the cosmetic comparison between the results of enucleation and evisceration.

We have confirmed the fact that after enucleation, in general, an orbital implant is desirable for better cosmetic result and motility. We did not find $\mathrm{AE}$ movement as good as has been reported elsewhere, ${ }^{411}$ but this may be due to differences in measurement techniques. We looked at absolute movement ratios rather than measuring angular deviation of the $\mathrm{AE}$, which we found difficult.

This study tends to confirm that, in general, after enucleation young adults do well and the elderly do badly. We also found that the very young did well in this study, though this was a relatively small group.

In summary, only the upper lid sulcus measurement was correlated significantly with cosmetic result. Other features were of lesser importance individu- ally. Techniques of excision of the eye which do not lead to sulcus formation would seem preferable. Further study is required before a particular method of excision could be recommended.

We were dismayed to find a number of $\mathrm{AE}$ fitting problems which we believe should have been avoided. Those who have had to undergo such a procedure should have the benefit of painstaking prosthetic fitting.

We thank the consultant staff at the Birmingham and Midland Eye Hospital for allowing us to investigate their patients. We also thank Mr Ivan Bradley, senior medical photographer, for his photographic assistance.

\section{References}

1 Witterman G, Scott R. Enucleation and evisceration. In: Peyman G, Sanders D, Goldberg M, eds. Principles and practice of ophthalmology. Philadelphia: Saunders, 1980: 2340.

2 Duke-Elder S. System of ophthalmology. London: Kimpton, 1965; 8: 1012-4.

3 Cooper WC. A method for volume determination of the orbit and its contents by high resolution axial tomography and quantitative digital analysis. Trans Am Ophthalmol Soc 1985; 83: 546-609.

4 Kennedy R. Growth retardation and volume determinations of the anophthalmic socket. Am J Ophthalmol 1973; 76: 294-302.

5 DeVoe A. Experiences with the surgery of the anophthalmic socket. Am J Ophthalmol 1945; 28: 1346-51.

6 Cutler N. Fascia-lata transplant for retrotarsal atrophy of upper lid following enucleation. Am J Ophthalmol 1946; 29: 176-9.

7 Hill J, Radford C. Treatment of advancing enophthalmos in the ocular prosthetic patient. A preliminary report including a warning. Am J Ophthalmol 1965; 60: 487-92.

8 Soll D. The anophthalmic socket. Ophthalmology 1982; 89: 407-23.

9 Roper-Hall M. Orbital implants. Trans Ophthalmol Soc UK 1954; 74: 337-46.

10 Myska V, Roper-Hall M. Late follow-up of acrylic magnetic orbital implants. Proc R Soc Med 1970; 63: 7-9.

Accepted for publication 17 July 1987. 